\title{
Psychological Distress during COVID-19 Lockdown among Dental Students and Practitioners in India: A Cross-Sectional Survey
}

\author{
Trishnika Chakraborty ${ }^{1, \odot}$ Gireesh Kumar Subbiah² \\ ${ }^{1}$ Department of Conservative Dentistry and Endodontics, I. T. S. \\ Dental College and Research Centre, Ghaziabad, Uttar Pradesh, India \\ 2Department of Clinical and Psychosocial Epidemiology, University \\ of Groningen, Groningen, The Netherlands \\ ${ }^{3}$ Department of Conservative Dentistry and Endodontics, MIDSR \\ Dental College, Maharashtra, India
}

Eur J Dent:2020;14(suppl S1):S70-S78
Yogesh Damade ${ }^{3}$

\begin{abstract}
Address for correspondence Trishnika Chakraborty, MDS, Department of Conservative Dentistry and Endodontics, I. T. S. Dental College and Research, Murad Nagar, Ghaziabad 201206, Uttar Pradesh, India (e-mail: trishnikasrija11@gmail.com).
\end{abstract}

\section{Abstract}

Keywords

- depression

- dentists

- dental students

- COVID-19

- psychological impact

- pandemic
Objective In response to the coronavirus disease 2019 (COVID-19) pandemic, the Indian Government imposed a countrywide lockdown of 21 days from March 25 to April 14, 2020, which was further extended to 60 days. The sudden draconian measures changed the delivery of dental education and practice throughout the country. The study aimed to screen for depression during the COVID-19 lockdown and the factors associated with it among dental students and practitioners in highly COVID-19 infected states of India.

Materials and Methods The current study is an online cross-sectional survey performed in Delhi NCR, Maharashtra, and Tamil Nadu during May 2020. The participants were recruited by convenience sampling. The main outcome measure was the screening of depression using the Patient Health Questionnaire (PHQ-9), which was categorized as mild, moderate, and severe depression. The data analysis was performed with IBM SPSS Version 23.0. A multivariable logistic regression model was fitted to identify the independent predictors of depression.

Results In total, 335 dental students and practitioners participated in the survey. Among this, a significant number of the dental students (54\%) and practitioners (44\%) scored moderate to severe depression in terms of depression severity according to the PHQ-9 scores. Those who were screened depressed were likely to be males and younger than 30 years old. The results of correlation analysis indicated that worry about the professional growth, concerns regarding setbacks in clinical and research experiences, previous history of mental health issues, and fear of contracting COVID-19 from patients were positively related to higher depression scores in students. Moreover, for practitioners, fear of contracting COVID-19 from the patients scored higher levels of depression. The practitioners who reported less concern about their practice/job post COVID-19 lockdown and those who were able to meet their financial expenses during the lockdown were the least likely to be depressed.

Conclusion The results of this study indicate a high level of depression among a significant number of dental students and practitioners. It is important to monitor and address the mental health needs of dental students and practitioners during and after the lockdown.
DOI https://doi.org/

10.1055/s-0040-1719211 ISSN $1305-7456$.
(C) 2020. European Journal of Dentistry.

This is an open access article published by Thieme under the terms of the Creative Commons Attribution-NonDerivative-NonCommercial-License, permitting copying and reproduction so long as the original work is given appropriate credit. Contents may not be used for commercial purposes, or adapted, remixed, transformed or built upon. (https://creativecommons.org/licenses/by-nc-nd/4.0/)

Thieme Medical and Scientific Publishers Pvt. Ltd., A-12, 2nd Floor, Sector 2, Noida-201301 UP, India 


\section{Introduction}

Coronavirus disease 2019 (COVID-19), an acute infectious viral disease caused by the novel coronavirus, that started in the Wuhan province of China and since then spread to 213 countries with the World Health Organization declaring it as a pandemic in March 2020.1,2 The figures of confirmed cases of COVID-19 in India increased exponentially from 727 in the month of March 2020 to $12,04,676$ as of July 2020, making it the third most affected country in the world. ${ }^{3}$ In response to the pandemic, the Indian Government imposed section 144 with a progressive lockdown of 21 days, from March 25 to April 14, 2020, which was further extended to 60 days. ${ }^{4,5}$ The drastic surge of infected patients notably impacted mental health among frontline healthcare workers as well as other healthcare providers, including dentists. ${ }^{6-8}$ Dental professionals are under the highest risk category for contracting COVID-19 infection due to close proximity of work in the oral cavity and direct contact through dental instruments, and exposed to aerosolized particles from respiratory droplets and oral mucosa. ${ }^{9,10}$ Because of the risks to dental students and practitioners, dental procedures are currently limited to emergency needs, affecting the broader dental training and practice. Furthermore, the lack of adequate personal protective equipment (PPE), high investment in clinical disinfection, and social stigma associated with the pandemic have added to the emotional burden. ${ }^{8}$ Given these unpredictable times for the practice of dentistry, it is crucial to screen for mental health concerns including depression among the Indian dental community. Understanding the depressive symptoms among dental students and practitioners and identifying the factors associated with it could help understand and identify suitable psychosocial interventions for this group.

\section{Aims and Research Questions}

The overall aim of the study was to screen for depression among dental students and practitioners based on three states with high numbers of COVID-19 infections, namely, Delhi NCR, Maharashtra, and Tamil Nadu. Second, we will identify the risk and protective factors associated with distress among dental students and practitioners.

The following research questions will be answered:

- Is there depression among dental students and practitioners as screened by the PHQ-9 questionnaire during the COVID-19 lockdown?

- What are the factors associated with depression among dental students and practitioners?

\section{Materials and Methods}

\section{Participants and Procedure}

An online survey consisting of self-rated questions for dental students and practitioners was performed between May 1, 2020 and May 10, 2020. Convenience sampling was used to recruit the participants through personal contacts and social media platforms such as Facebook and WhatsApp. All the respondents provided informed consent, and the data were collected anonymously.

\section{Questionnaire}

The 2-minute survey consisted of four parts: basic demographic data, mental health assessment using the PHQ-9, questions pertaining to dental students and practitioners, and feedback regarding the survey. The procedures of this study complied with the provisions of the Declaration of Helsinki regarding research on human participants.

\section{Demographic Data}

The demographic data included questions on gender (male or female), age, current professional status (undergraduate student, postgraduate student, intern, private practitioner, consultant dentist, or academic staff), previous history of mental health issues (yes or no), fear of contracting COVID-19 from patients because of the profession (yes or no), and current living setting (alone, with family, or with flat mates).

\section{Mental Health Assessment}

Depression was screened using the Patient Health Questionnaire-9 (PHQ-9). It is a self-reported measure for screening depression on a 4-point Likert-type scale ranging from not at all experiencing the symptoms to experiencing them nearly every day for the past 4 weeks. The overall scores of the questionnaire are categorized as minimal/no depression (0-4), mild depression (5-9), moderate depression (10$14)$, or severe depression (15-27) $)^{11}$. This scale has also been widely used with Indian populations and has demonstrated excellent psychometric properties (sensitivity, $87.1 \%$; specificity, 79.7\%; and Cronbach's $\alpha, 0.87)^{12}$.

\section{Questions Pertaining to the Dental Students}

The following questions were asked for the dental students to assess the changes in clinical and theoretical training: are you worried about your professional growth due to decrease in training activity, if virtual teaching is efficient to train and prepare the clinical scenarios that one cannot see and perform in dental school, and the aspect of the dental education cycle which will be most affected by the COVID-19? Furthermore, a question on the preference for the method of education during the lockdown was added.

\section{Questions Pertaining to the Practitioners}

The following questions were included for practitioners: the job setting of the participant (private hospital, private clinic, university, or government hospital), are you able to meet the (clinic and living) expenses during the lockdown, are you worried about your practice post COVID-19 lockdown, and how are dentists making themselves productive (emergency dental procedures, attending/taking online classes, other sources of income, or tele-practice)?

\section{Statistical Analyses}

Data analysis was performed with IBM SPSS Version 23.0. The sample size was calculated using the formula for comparing proportions as $n=Z^{2} \mathrm{pq} / \mathrm{d}^{2}$ with a prevalence percentage of $5 \%$ depression and with $95 \%$ level of confidence and margin of error as $5 \%$. To determine the severity of depression among the respondents, individual questions were graded 
into total depression scores. We categorized the respondents into no depression (below 10) and depression (10 and above) by taking a recommended cutoff score of $10 .{ }^{13}$ The sociodemographic characteristics and the percentage of participants self-reported as depression were presented as descriptive statistics. Bivariate analysis of factors associated with depression was performed using Spearman's correlation ( $r$ ) as well as Chi-square test of independence. A multivariable logistic regression model was fitted to identify the independent predictors of depression while adjusting for confounders with the odds ratio (OR) with a $95 \%$ confidence interval (CI). A two-tailed $p<0.05$ was considered statistically significant for this study.

\section{Results}

\section{Sample Characteristics}

In total, 335 participants, including 168 students and 167 practitioners, completed the survey. Most of the respondents were females, that is, 240 (72\%), and the mean age was 24 and 31 years for dental students and practitioners, respectively. Among all the respondents, approximately two-thirds (256, 93.4\%) lived with their family, 254 (77\%) did not have a previous record of psychological condition, and most participants (222, 65\%) had fear of contracting COVID-19 from their patients because of their profession. The other sample characteristics are summarized in $\boldsymbol{- T a b l e} \mathbf{1}$.

\section{Mental Health Assessment}

According to the classification of the PHQ-9 scores, the students and practitioners were divided into four groups. Among the sample of 168 students, approximately $12 \%$ had no depression, whereas the proportions of students with mild, moderate, and severe depression were 34,27 , and $27 \%$, respectively. Among the sample of 167 practitioners, approximately $18 \%$ had no depression, whereas the proportions of practitioners with mild, moderate, and severe depression were 38,22 , and $22 \%$, respectively, as presented in $\boldsymbol{- F i g .} \mathbf{1}$ and $\boldsymbol{- T a b l e ~} \mathbf{2}$.

\section{Factors Associated with Students' and Practitioners' Depression during the Pandemic Lockdown}

Correlation analysis: The results of the correlation analysis of students are shown in - Table $\mathbf{3}$ and of practitioners in - Table 4. For students, worry about professional growth due to a decrease in training activity was positively related to depres$\operatorname{sion}(\mathrm{R}=0.1860, p<0.05)$. Moreover, the aspects of the dental education cycle affected by the COVID-19 lockdown $(R=0.2801$, $p<0.05)$, previous records of mental health issues $(R=0.2348$, $p<0.05$ ), and fear of contracting COVID-19 from patients $(\mathrm{R}=0.2406, p<0.05)$ were positively related to depression scores.

For practitioners, gender $(R=0.2316)$, worry about dental practice post COVID-19 lockdown $(R=0.5320)$, previous record of mental health issues $(R=0.2478)$, loss of current job $(R=0.2488)$, and fear of contracting COVID-19 from patients $(\mathrm{R}=0.2981)$ were positively related to depression scores. However, age $(R=-0.2933)$ and influence on expenses during the lockdown $(R=-0.3164)$ were negatively related to depression.

\section{Bivariate Analysis}

The bivariate analysis of contributing factors for depression among dental students is shown in - Table $\mathbf{5}$. The significant

Table 1 Study sample demographic characteristics

\begin{tabular}{|c|c|c|c|c|}
\hline Variables & & $\begin{array}{l}\text { Practitioners } \\
(n=167)\end{array}$ & $\begin{array}{l}\text { Students } \\
(n=168)\end{array}$ & $\begin{array}{l}\text { Total } \\
(n=335)\end{array}$ \\
\hline Age (mean, SD) & & $31(4)$ & $24(3)$ & $27(5)$ \\
\hline \multirow[t]{2}{*}{ Gender } & Female & 105 (63\%) & $137(82 \%)$ & $240(72 \%)$ \\
\hline & Male & $61(37 \%)$ & 31 (19\%) & $92(28 \%)$ \\
\hline \multirow{6}{*}{$\begin{array}{l}\text { Current professional } \\
\text { status }\end{array}$} & Academic Staff & $23(14 \%)$ & & $23(7 \%)$ \\
\hline & BDS student & & $67(40 \%)$ & $65(20 \%)$ \\
\hline & Consultant dentist & $48(29 \%)$ & & $48(14 \%)$ \\
\hline & Dental practitioner & $96(57 \%)$ & & 95 (29\%) \\
\hline & Intern & & $33(20 \%)$ & $33(10 \%)$ \\
\hline & MDS student & & $68(41 \%)$ & $68(20 \%)$ \\
\hline \multirow{3}{*}{$\begin{array}{l}\text { Current living } \\
\text { situation }\end{array}$} & Alone & $6(4 \%)$ & $11(7 \%)$ & $17(5 \%)$ \\
\hline & With family & $152(92 \%)$ & 157 (90\%) & 301 (91\%) \\
\hline & With flat mates & $8(5 \%)$ & $6(4 \%)$ & $14(4 \%)$ \\
\hline \multirow{2}{*}{$\begin{array}{l}\text { Previous history of } \\
\text { mental health issues }\end{array}$} & No & $132(80 \%)$ & $124(73 \%)$ & $254(77 \%)$ \\
\hline & Yes & $34(20 \%)$ & $44(27 \%)$ & $78(23 \%)$ \\
\hline \multirow{2}{*}{$\begin{array}{l}\text { Fear of contracting } \\
\text { COVID-19 }\end{array}$} & No & $63(37 \%)$ & $49(29 \%)$ & $112(33 \%)$ \\
\hline & Yes & $104(62 \%)$ & $118(70 \%)$ & $222(66 \%)$ \\
\hline
\end{tabular}

Abbreviations: BDS, bachelor of dental surgery; MDS, master of dental surgery; SD, standard deviation. 
variables affecting depression were concerns about setbacks in clinical training, previous records of mental health issues, and fear of contracting COVID-19 from patients. Other variables did not reach statistical significance.

- Table 6 presents the bivariate analysis of contributing factors for depression among practitioners. Depression was significantly higher among males and for the younger population ( $<30$ years) and those with difficulty in meeting expenses. It was also significantly higher for those who may have a previous history of mental health problems, who faced difficulty finding a new job and those who are seriously worried about their practice/job post COVID-19 lockdown.

\section{Logistic Regression}

The results of the logistic regression on the factors associated with depression are presented in -Tables $\mathbf{7}$ and $\mathbf{8}$.

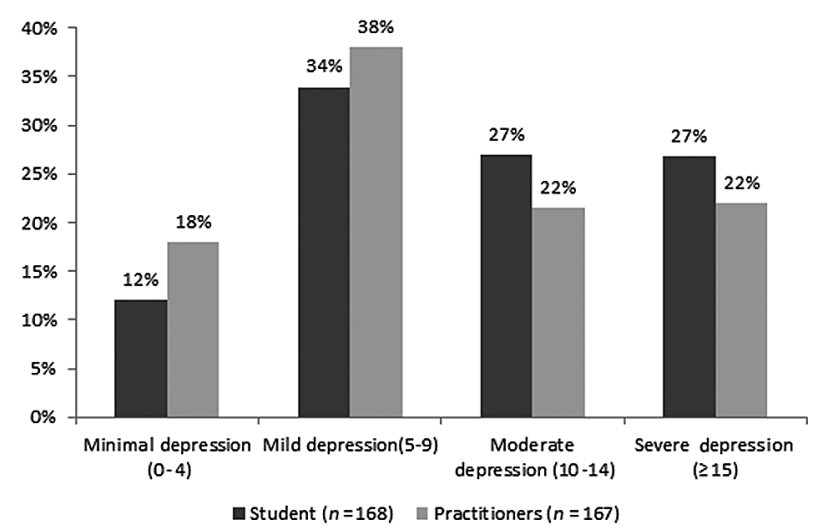

Fig. 1 Graph showing the percentage of the categories of depression based on the PHQ-9 scores among dental students and practitioners.
For dental students, the fear of contracting COVID-19 from patients (odds ratio [OR]: 2.5, 95\% confidence interval [CI]: 1.08-5.80) and a previous history of mental illness (OR: 4.33, 95\% CI: $1.25-14.9)$ were significant contributing factors for depression. For practitioners, the significant contributing factor for depression was fear of contracting COVID-19 from the patients (OR: 5.56, 95\% CI: 1.86-16.64). The practitioners who reported less concern about their practice/job post COVID-19 lockdown and those who were able to meet their financial expenses during the lockdown were the least likely to be depressed.

\section{Discussion}

Previous studies have described the psychological distress of public health emergencies such as epidemics, which were screened as anxiety, fear, and worry among the general population. ${ }^{6}$ According to a previous study, the prevalence of psychological distress in dentists has been related to the fear of contracting COVID-19. ${ }^{14}$ Furthermore, a recent study also found the prevalence of depression among non-frontline health workers and students, which was significantly associated with limitations in training and practice, stigmatization targeting doctors as projected by the media, and a significant decrease in patient flow owing to difficulty in financial sustainability. ${ }^{15}$ The current study evaluated the psychological impact in Indian dental trainees and dental practitioners during the COVID-19 lockdown and explored the possible factors influencing the impact, as confirmed by studies. The results of this study found a high prevalence of depression among dental practitioners and students in India, and were also in line with a previous study among dentists performed in Israel. ${ }^{14}$

Table 2 Severity of depression according to Public Health Questionnaire-9 among students and practitioners

\begin{tabular}{|l|l|l|l|l|}
\hline Diagnosis & Total score & $\begin{array}{l}\text { Students } \\
(\boldsymbol{n}=168)\end{array}$ & $\begin{array}{l}\text { Practitioners } \\
(\boldsymbol{n}=167)\end{array}$ & $\begin{array}{l}\text { Total } \\
(\boldsymbol{n}=335)\end{array}$ \\
\hline Minimal depression & 4 below & $21(12 \%)$ & $30(18 \%)$ & $51(15 \%)$ \\
\hline Mild depression & $5-9$ & $57(34 \%)$ & $63(38 \%)$ & $120(36 \%)$ \\
\hline Moderate depression & $10-14$ & $45(27 \%)$ & $37(22 \%)$ & $82(24 \%)$ \\
\hline Severe depression & 15 above & $45(27 \%)$ & $36(22 \%)$ & $81(24 \%)$ \\
\hline Depression & 10 and above & $90(53 \%)$ & $73(43 \%)$ & $163(48 \%)$ \\
\hline No depression & Below 10 & $79(48 \%)$ & $94(57 \%)$ & $173(53 \%)$ \\
\hline
\end{tabular}

Table 3 Correlation between depression scores with various independent variables of students by Spearman R method

\begin{tabular}{|l|l|l|l|}
\hline Related stressors & \multicolumn{3}{|c|}{ Correlation analysis with depression } \\
\cline { 2 - 4 } & Spearman R & $t$-value & \multicolumn{1}{c|}{$\boldsymbol{p}$-level } \\
\hline Worry about professional growth due to decrease in training activity? & 0.1860 & 2.4388 & $0.0158^{\mathrm{a}}$ \\
\hline Do you feel dental application cycle is the most affected by COVID-19? & 0.2801 & 3.7597 & $0.0002^{\mathrm{a}}$ \\
\hline Any previous record of mental health issues? & 0.2348 & 3.1125 & $0.0022^{\mathrm{a}}$ \\
\hline Fear contracting COVID-19 from patients because of your profession? & 0.2406 & 3.1843 & $0.0017^{\mathrm{a}}$ \\
\hline
\end{tabular}

${ }^{a}$ represents the test was significant with $\mathrm{p} \leq 0.05$ 
S74 Impact of Dental Students and Practitioners during COVID-19 in India Chakraborty et al.

Table 4 Correlation between depression scores with various independent variables of practitioners by Spearman R method

\begin{tabular}{|l|l|l|l|}
\hline Related stressors & \multicolumn{3}{|c|}{ Correlation analysis } \\
\cline { 2 - 4 } & Spearman R & $t$-value & $p^{-l e v e l}$ \\
\hline Age $(y)$ & -0.2933 & -3.9403 & $0.0001^{\text {a }}$ \\
\hline Gender & 0.2316 & 3.0583 & $0.0026^{\text {a }}$ \\
\hline Worry about your practice/job post COVID-19 lockdown? & 0.5320 & 8.0696 & $0.0001^{\text {a }}$ \\
\hline Able to meet expenses during the lockdown? & -0.3164 & -4.2850 & $0.0001^{\text {a }}$ \\
\hline Any previous record of mental health issues? & 0.2478 & 3.2855 & $0.0012^{\text {a }}$ \\
\hline Lose your current job? & 0.2488 & 3.2997 & $0.0012^{\text {a }}$ \\
\hline Fear contracting COVID-19 from patients because of your profession? & 0.2981 & 4.0120 & $0.0001^{\text {a }}$ \\
\hline
\end{tabular}

${ }^{a} p<0.05$ indicates significant correlation with depression.

Table 5 Bivariate association between levels of depression with other variables for dental practitioners

\begin{tabular}{|c|c|c|c|c|c|}
\hline Factors & $\begin{array}{l}\text { No } \\
\text { depression }\end{array}$ & $\begin{array}{l}\text { With } \\
\text { depression }\end{array}$ & Total & Chi-square & $p$-Value \\
\hline \multicolumn{6}{|l|}{ Age groups } \\
\hline$<24$ & 42 & 44 & 86 & 0.9210 & 0.3370 \\
\hline $24-30$ & 34 & 48 & 82 & & \\
\hline \multicolumn{6}{|l|}{ Gender } \\
\hline Male & 14 & 17 & 31 & 0.0001 & 0.9920 \\
\hline Female & 62 & 75 & 137 & & \\
\hline \multicolumn{6}{|l|}{ Current professional status } \\
\hline BDS student & 34 & 33 & 67 & 1.9040 & 0.3860 \\
\hline Intern & 12 & 21 & 33 & & \\
\hline MDS student & 30 & 38 & 68 & & \\
\hline \multicolumn{6}{|c|}{ Worried about professional growth due to decrease in training activity? } \\
\hline No & 6 & 2 & 8 & 5.8540 & 0.1190 \\
\hline To certain extent & 13 & 15 & 28 & & \\
\hline Yes considerably & 57 & 75 & 132 & & \\
\hline \multicolumn{6}{|c|}{ Do you feel dental application cycle is the most affected by COVID-19? } \\
\hline Clinical experience & 57 & 53 & 110 & 7.5750 & $0.0230^{\mathrm{a}}$ \\
\hline Research Experiences/thesis & 4 & 16 & 20 & & \\
\hline Others & 15 & 23 & 38 & & \\
\hline \multicolumn{6}{|l|}{ Current living situation } \\
\hline Alone & 5 & 6 & 11 & & \\
\hline With family & 71 & 86 & 157 & 0.0000 & 0.9880 \\
\hline \multicolumn{6}{|c|}{ Any previous record of mental health issues? } \\
\hline No & 63 & 61 & 124 & 10.1720 & $0.0060^{\mathrm{a}}$ \\
\hline Yes & 13 & 31 & 44 & & \\
\hline \multicolumn{6}{|c|}{ Fear contracting COVID-19 from patients? } \\
\hline No & 31 & 18 & 49 & 8.8220 & $0.0120^{\mathrm{a}}$ \\
\hline Yes & 45 & 73 & 118 & & \\
\hline Total & 76 & 91 & 167 & & \\
\hline
\end{tabular}


Table 6 Bivariate association between levels of depression with other variables for dental practitioners

\begin{tabular}{|c|c|c|c|c|c|}
\hline Factors & $\begin{array}{l}\text { No } \\
\text { depression }\end{array}$ & $\begin{array}{l}\text { With } \\
\text { depression }\end{array}$ & Total & Chi-square & $p$-Value \\
\hline \multicolumn{6}{|l|}{ Age groups } \\
\hline$<30$ & 35 & 49 & 84 & 15.1860 & $0.0020^{\mathrm{a}}$ \\
\hline $31-35$ & 43 & 18 & 61 & & \\
\hline $36-40$ & 11 & 3 & 14 & & \\
\hline$>41$ & 4 & 4 & 8 & & \\
\hline \multicolumn{6}{|l|}{ Gender } \\
\hline Male & 44 & 19 & 63 & 8.2110 & $0.0040^{\mathrm{a}}$ \\
\hline Female & 49 & 55 & 104 & & \\
\hline \multicolumn{6}{|l|}{ Current professional status } \\
\hline Dental practitioner & 56 & 40 & 96 & 1.6130 & 0.4460 \\
\hline Consultant dentist & 22 & 24 & 46 & & \\
\hline Academic staff & 15 & 10 & 25 & & \\
\hline \multicolumn{6}{|c|}{ Are you worried about your practice/job post COVID-19 lockdown? } \\
\hline Not at all & 11 & 0 & 11 & 37.1980 & $0.0001^{\mathrm{a}}$ \\
\hline Mild worry & 43 & 15 & 58 & & \\
\hline Considerable worry & 39 & 59 & 98 & & \\
\hline \multicolumn{6}{|l|}{ Able to meet expenses during the lockdown? } \\
\hline With difficulty & 43 & 52 & 95 & 15.8870 & $0.0001^{\mathrm{a}}$ \\
\hline Other source of income & 24 & 18 & 42 & & \\
\hline Easily & 26 & 4 & 30 & & \\
\hline \multicolumn{6}{|l|}{ Previous record of mental health issues? } \\
\hline No & 81 & 52 & 133 & 17.8210 & $0.0001^{\mathrm{a}}$ \\
\hline Yes & 12 & 22 & 34 & & \\
\hline \multicolumn{6}{|l|}{ Lost your current job? } \\
\hline No & 54 & 34 & 88 & 7.1380 & $0.0280^{\mathrm{a}}$ \\
\hline $\begin{array}{l}\text { No, but I have not received my salary } \\
\text { during the lockdown }\end{array}$ & 26 & 17 & 43 & & \\
\hline $\begin{array}{l}\text { Yes, and it is difficult to find a new } \\
\text { job }\end{array}$ & 13 & 23 & 36 & & \\
\hline \multicolumn{6}{|c|}{ Fear contracting COVID-19 from patients because of your profession? } \\
\hline No & 53 & 10 & 63 & 33.4250 & $0.0001^{\mathrm{a}}$ \\
\hline Yes & 40 & 64 & 104 & & \\
\hline Total & 93 & 74 & 167 & & \\
\hline
\end{tabular}

With respect to the students, $54 \%$ of them scored moderate to high in terms of depression severity according to the PHQ-9 questionnaire during the lockdown. However, the depression scores among the dental students before the pandemic in 2019 ranged between 9.8 and 2.5\% in terms of moderate to severe depression. Before the pandemic, the contributing factors to depression were closely associated with relationship status and satisfaction in dentistry. ${ }^{16}$ In this study, during the COVID-19 lockdown, depression among $60 \%$ of the students was associated with worry about professional growth due to reduced clinical training. Furthermore, potential professional growth, concern about clinical experiences and research experience, and other factors such as employment prospects are attributed to depression in 42,53 , and $60 \%$, respectively. The results of this study also indicated higher depression among students who were afraid of contracting COVID-19 during clinical postings. Deficient clinical training, especially among interns (unable to fulfil the clinical quota, increased course completion length), will indeed be detrimental for professional growth and future employment. ${ }^{16,17}$ A previous history of mental health problems also showed a significant association with depression among students. The findings of our study are similar to 
Table 7 Multiple logistic regression analysis for various factors on depression among dental students

\begin{tabular}{|c|c|c|c|c|}
\hline \multirow[t]{2}{*}{ Factors } & \multirow{2}{*}{$\begin{array}{c}\text { Adjusted } \\
\text { OR }\end{array}$} & \multicolumn{2}{|c|}{$95 \% \mathrm{CI}$ for OR } & \multirow[t]{2}{*}{$p$-Value } \\
\hline & & Lower & Upper & \\
\hline \multicolumn{5}{|l|}{ Age groups } \\
\hline$<24$ y & \multicolumn{4}{|l|}{ Ref. } \\
\hline $24-30 y$ & 2.06 & 0.57 & 7.42 & 0.2680 \\
\hline \multicolumn{5}{|l|}{ Gender } \\
\hline Male & \multicolumn{4}{|l|}{ Ref. } \\
\hline Female & 0.71 & 0.29 & 1.75 & 0.4600 \\
\hline \multicolumn{5}{|c|}{ Current professional status } \\
\hline $\begin{array}{l}\text { BDS } \\
\text { student }\end{array}$ & \multicolumn{4}{|l|}{ Ref. } \\
\hline Intern & 1.74 & 0.63 & 4.83 & 0.2880 \\
\hline $\begin{array}{l}\text { MDS } \\
\text { student }\end{array}$ & 0.66 & 0.16 & 2.70 & 0.5600 \\
\hline \multicolumn{5}{|c|}{$\begin{array}{l}\text { Worried about professional growth due to decrease in training } \\
\text { activity? }\end{array}$} \\
\hline No & \multicolumn{4}{|l|}{ Ref. } \\
\hline $\begin{array}{l}\text { To certain } \\
\text { extent }\end{array}$ & 0.80 & 0.19 & 3.43 & 0.7670 \\
\hline $\begin{array}{l}\text { Yes } \\
\text { considerably }\end{array}$ & 1.06 & 0.28 & 3.96 & 0.9310 \\
\hline \multicolumn{5}{|c|}{ Current living situation } \\
\hline Alone & Ref. & & & \\
\hline With family & 0.52 & 0.17 & 1.60 & 0.2510 \\
\hline \multicolumn{5}{|c|}{ Previous history of mental health issues } \\
\hline No & Ref. & & & \\
\hline Yes & 4.33 & 1.25 & 14.99 & $0.0210^{\mathrm{a}}$ \\
\hline \multicolumn{5}{|c|}{ Fear contracting COVID-19 from patients } \\
\hline No & Ref. & & & \\
\hline Yes & 2.50 & 1.08 & 5.80 & $0.0330^{\mathrm{a}}$ \\
\hline
\end{tabular}

Abbreviations: BDS, Bachelor of Dental Surgery; MDS, Master of Dental Surgery; OR, odds ratio.

those of previous studies in which a previous history of mental health problems was associated with the current status of depression. ${ }^{18-20}$

In our study, $58 \%$ of the dental practitioners who scored moderate/severe depression were below the age of 30 years. There was a significant level of depression among young practitioners, who were finding it difficult to meet the clinic and living expenses during the lockdown. It is most likely that younger practitioners are in the initial stage of establishing their practices and could also have financial obligations to fulfill, such as repayment of education and business loans. ${ }^{15}$ The results of this study indicated that dentists' depression was associated with resuming practice post the lockdown, which in turn may be due to uncertainties surrounding the job prospects and further financial burden from investing in additional
Table 8 Multiple logistic regression analysis for various factors on depression among practitioners

\begin{tabular}{|c|c|c|c|c|}
\hline \multirow{2}{*}{$\begin{array}{l}\text { Independent } \\
\text { variables }\end{array}$} & \multirow{2}{*}{$\begin{array}{l}\text { Adjusted } \\
\text { OR }\end{array}$} & \multicolumn{2}{|c|}{$95 \% \mathrm{Cl}$ for OR } & \multirow[t]{2}{*}{$p$-Value } \\
\hline & & Lower & Upper & \\
\hline \multicolumn{5}{|l|}{ Age groups } \\
\hline$<30$ & \multicolumn{4}{|l|}{ Ref. } \\
\hline $31-35$ & 0.45 & 0.18 & 1.11 & 0.0830 \\
\hline $36-40$ & 0.54 & 0.10 & 3.03 & 0.4870 \\
\hline$>41$ & 2.61 & 0.43 & 15.86 & 0.2980 \\
\hline \multicolumn{5}{|l|}{ Gender } \\
\hline Male & \multicolumn{4}{|l|}{ Ref. } \\
\hline Female & 1.42 & 0.56 & 3.61 & 0.4630 \\
\hline \multicolumn{5}{|c|}{ Current professional status } \\
\hline $\begin{array}{l}\text { Dental } \\
\text { practitioner }\end{array}$ & \multicolumn{4}{|l|}{ Ref. } \\
\hline $\begin{array}{l}\text { Consultant } \\
\text { dentist }\end{array}$ & 1.78 & 0.64 & 4.93 & 0.2710 \\
\hline $\begin{array}{l}\text { Academic } \\
\text { staff }\end{array}$ & 0.64 & 0.18 & 2.24 & 0.4840 \\
\hline \multicolumn{5}{|c|}{$\begin{array}{l}\text { Are you worried about your practice/job post COVID-19 } \\
\text { lockdown? }\end{array}$} \\
\hline Not at all & \multicolumn{4}{|l|}{ Ref. } \\
\hline Mild worry & 0.15 & 0.04 & 0.52 & $0.0030^{\mathrm{a}}$ \\
\hline $\begin{array}{l}\text { Considerable } \\
\text { worry }\end{array}$ & 0.86 & 0.24 & 3.11 & 0.8220 \\
\hline \multicolumn{5}{|c|}{ Able to meet expenses during the lockdown? } \\
\hline $\begin{array}{l}\text { With } \\
\text { difficulty }\end{array}$ & \multicolumn{4}{|l|}{ Ref. } \\
\hline $\begin{array}{l}\text { Other source } \\
\text { of income }\end{array}$ & 0.50 & 0.18 & 1.42 & 0.1930 \\
\hline Easily & 0.15 & 0.03 & 0.70 & $0.0160^{\mathrm{a}}$ \\
\hline \multicolumn{5}{|c|}{ Previous history of mental health issues? } \\
\hline No & \multicolumn{4}{|l|}{ Ref. } \\
\hline Yes & 0.45 & 0.13 & 1.55 & 0.2050 \\
\hline \multicolumn{5}{|c|}{ Did you lose your current job? } \\
\hline No & \multicolumn{4}{|l|}{ Ref. } \\
\hline $\begin{array}{l}\text { No, but I } \\
\text { have not } \\
\text { received my } \\
\text { salary during } \\
\text { the lockdown }\end{array}$ & 1.31 & 0.47 & 3.67 & 0.6030 \\
\hline $\begin{array}{l}\text { Yes, and I am } \\
\text { unemployed } \\
\text { now }\end{array}$ & 2.20 & 0.71 & 6.77 & 0.1700 \\
\hline \multicolumn{5}{|c|}{ Fear of contracting COVID-19 from the patients? } \\
\hline No & Ref. & & & \\
\hline Yes & 5.56 & 1.86 & 16.64 & $0.0020^{\mathrm{a}}$ \\
\hline
\end{tabular}

Abbreviations: $\mathrm{Cl}$, confidence interval; OR, odds ratio.

protective gear against COVID-19. Additionally, the fear of contracting COVID-19 from patients showed a significant association with depression among the practitioners. 


\section{Mitigation Measures}

It is the need of the hour to recognize the importance of mental health among the dental fraternity and mobilizing a rapid therapeutic response team either through video or tele-counseling through digital platforms. It should also be important to take into account the previous history of mental health concerns and have a special focus on this subgroup. In our opinion, social media can be used to identify every depression coping/risk profile, which can be used as a tool to enhance psychological screening and intervention.

Students: Our present study indicated that $55 \%$ of the respondents considered the webinars not to be efficient for clinical training, and most students who attended more than five webinars/seminars in a week found webinars confusing. Given the situation, a suitable alternative to in-person training would be the use of augmented reality (AR) dental simulators such as DentSim (Novint Technologies), the MOOG Simodont Dental Trainer, and the IDSS (Iowa Dental Surgical Simulator).. ${ }^{21}$ The Anatomage Table (San Jose, California, United States) is also an academic friendly, hands-on diagnostic tool for Oral and Maxillofacial Surgery postgraduates to virtually dissect a digital cadaver ${ }^{22}$. In addition, certified hands-on courses-by creating virtual reality 360 degrees dental procedures-webinars from experts and pairing students for a group academic presentation with a virtual mentor can be alternatives to didactic teaching. Furthermore, the dental colleges could formulate measures to assist the current interns for junior residency programs in private and government hospitals to overcome the loss of training period of internship due to closure of colleges.

Practitioners: This study indicated that $35.8 \%$ of the dental practitioners during the lockdown were practicing only emergency dental procedures, while $32.7 \%$ of the practitioners were attending or conducting their own webinars. First, a survey on patient attitudes toward dental treatment during COVID-19 can help us predict the patient volume in the coming months. Furthermore, the data can be used to develop strategies such as the use of social media platforms to showcase the hygiene maintained in dental practice and rumors on clinical disinfection and sterilization. ${ }^{23}$ Currently, some dental practitioners have contributed as COVID-19 warriors by involving screening and recording data of COVID-19 patients in COVID hospitals and NGOs (http://doctorsforyou.org/). This resulted in financial improvement and helped them overcome the stigma and fear of contracting infection. Another common scenario in India is quack dental practices, which function in full swing during the lockdown, and steps should be taken to eradicate such practices, as they affect the patient's attitude toward dental treatment and add up to mental and financial burden for private clinicians in that locality. ${ }^{10,24}$ The financial situation in the dental field is alarming and requires immediate financial support by the government, which should be available to dental practitioners to counter the losses sustained and to meet their urgent needs. Moreover, dental insurance for all clinics, flexibility to businesses filing taxes and including dental treatment in all health care policies can significantly help dental clinics overcome financial losses due to the COVID-19 outbreak. ${ }^{25}$

\section{Limitations}

Despite the important findings, the limitations of this cross-sectional study preclude causal inferences, limited period of study sampling, and confounding bias. Moreover, not all the questions in the surveys are standardized. Additionally, the PHQ-9 questionnaire is best used as a screening tool only for major depressive disorder and cannot by itself replace the evaluation of a psychiatrist or physician, which is a limitation. Though it gives cut-off scores that can be correlated to clinical severity, the actual diagnosis must be done using a clinical diagnostic tool of DSM-5, administered by a clinician, and treatment should be based on that diagnosis. Lastly, online self-assessments and nonrigorous random sampling could have reduced the representativeness and reliability of the results.

\section{Conclusion}

Within the limitations of this study, there was a significant prevalence of depression among dental trainees and practitioners during the COVID-19 lockdown. In summary, the contributing factors for screened depression in dental practitioners were fear of contracting COVID-19 from patients, previous record of mental health issues, worry about the practice post lockdown, concerns about practice/job post the COVID-19 lockdown, and loss of current job due to pandemic. Majorly, depression was prevalent among male working dentists who were below 30 years of age. Among dental students, depression might be due to deficient clinical training and research experiences, worry about professional growth due to lack of sufficient training, and fear of contracting COVID-19 during postings from patients. Hence, the government and dental schools should collaborate to provide continuous and comprehensive mental healthcare services even for subthreshold and mild psychological distress during this crisis to attenuate the possibility of escalating complications.

\section{Note}

All authors have read and agreed to the published version of the manuscript.

\section{Funding}

None.

\section{Conflict of Interest}

None declared.

\section{Acknowledgments}

The authors would like to acknowledge the association of I.T.S Dental College, MIDSR Dental College, Saveetha Dental College and Sri Ramachandra Dental College for their help in distributing the survey among Indian dental students. The authors would acknowledge the help of Dr. Gyanendra Pratap Singh and Kritika Subbiah in data collection. 


\section{References}

1 Chan JF-W, Yuan S, Kok KH, et al. A familial cluster of pneumonia associated with the 2019 novel coronavirus indicating person-to-person transmission: a study of a family cluster. Lancet 2020;395(10223):514-523

2 WHO. 2020. Statement on the second meeting of the International Health Regulations (2005)Emergency Committee regarding the outbreak of novel coronavirus (2019 nCoV). Available at: https://www.who.int/news-room/detail/30-012020-statement-on-the-second-meeting-of-theinternational-health-regulations-(2005)-emergency-committee-regarding-the-outbreak-of-novelcoronavirus-(2019-ncov). Assessed February 15, 2020

3 Coronavirus Update (Live). 12,04,676 cases and 153,923 deaths from COVID-19 virus pandemic - Covid19India.org (n.d.). Available at: https://www.covid19india.org/. Accessed July 18, 2020

4 BBC news. Available at: https://www.bbc.com/news/worldasiaindia-52024239. Accessed June 14, 2020

5 Livemint. Available at: https://www.livemint.com/news/ india/lockdown-extended-till-17-may-whatwill-open-remainclosed-11588340829516.html. Accessed May 14, 2020

6 Vergara-Buenaventura A, Chavez-Tuñon M, Castro-Ruiz C. The Mental Health Consequences of Coronavirus Disease 2019 Pandemic in Dentistry [published online ahead of print, 2020 Jun 5]. Disaster Med Public Health Prep 2020;1-4 doi:10.1017/ dmp.2020.190

7 Shacham M, Hamama-Raz Y, Kolerman R, Mijiritsky O, Ben-Ezra M, Mijiritsky E. COVID-19 factors and psychological factors associated with elevated psychological distress among dentists and dental hygienists in Israel. Int J Environ Res Public Health 2020;17(8):2900

8 Khanna RC, Honavar SG, Metla AL, Bhattacharya A, Maulik PK. Psychological impact of COVID-19 on ophthalmologists-in-training and practising ophthalmologists in India. Indian J Ophthalmol 2020;68(6):994-998

9 Meng L, Hua F, Bian Z. Coronavirus disease 2019 (COVID-19): emerging and future challenges for dental and oral medicine. J Dent Res 2020;99(5):481-487

10 Ahmed MA, Jouhar R, Ahmed N, et al. Fear and practice modifications among dentists to combat novel coronavirus disease (COVID-19) outbreak. Int J Environ Res Public Health 2020;17(8):E2821

11 Kocalevent RD, Hinz A, Brähler E. Standardization of the depression screener patient health questionnaire (PHQ-9) in the general population. Gen Hosp Psychiatry 2013;35(5):551-555

12 Indu PS, Anilkumar TV, Vijayakumar K, et al. Reliability and validity of PHQ-9 when administered by health workers for depression screening among women in primary care. Asian J Psychiatr 2018;37:10-14

13 Manea L, Gilbody S, McMillan D, McMillan D. Optimal cutoff score for diagnosing depression with the Patient Health Questionnaire (PHQ-9): a meta-analysis. CMAJ 2012;184(3): E191-E196

14 Shacham M, Hamama-Raz Y, Kolerman R, Mijiritsky O, Ben-Ezra M, Mijiritsky E. COVID-19 factors and psychological factor sassociated with elevated psychological distress among dentists and dental hygienists in Israel. Int J Environ Res Public Health 2020;17(8):E2900

15 Consolo U, Bellini P, Bencivenni D, Iani C, Checchi V. Epidemiological aspects and psychological reactions to COVID-19 of dental practitioners in the Northern Italy Districts of Modena and Reggio Emilia. Int J Environ Res Public Health 2020;17(10):E3459

16 Raghunathan D, Ramakrishnan D, Iris Valsan KV, Ambika S. Prevalence of depression among students of a dental tertiary care center in Kerala. Indian J Community Med 2019;44, Suppl 1) :S14-S18

17 Potts JR II. Residency and fellowship program accreditation: Effects of the novel coronavirus (COVID-19) pandemic. J Am Coll Surg 2020;230(6):1094-1097

18 Chatterjee SS, Barikar C M, Mukherjee A. Impact of COVID-19 pandemic on pre-existing mental health problems. [published online ahead of print, April 18, 2020] Asian J Psychiatr 2020;51:102071

19 Liu X, Kakade M, Fuller CJ, et al. Depression after exposure to stressful events: lessons learned from the severe acute respiratory syndrome epidemic. Compr Psychiatry 2012;53(1):15-23

20 Kennedy N, Abbott R, Paykel ES. Remission and recurrence of depression in the maintenance era: long-term outcome in a Cambridge cohort. Psychol Med 2003;33(5):827-838

21 Tavkar A, Pawar A. Simulation in dentistry. EC Dent Sci 2017;12(3):115-121

22 Zingaretti N, Contessi Negrini F, Tel A, Tresoldi MM, Bresadola V, Parodi PC. The impact of COVID-19 on plastic surgery residency training. Aesthetic Plast Surg 2020;44(4): 1381-1385

23 Sarfaraz S, Shabbir J, Mudasser MA, et al. Knowledge and attitude of dental practitioners related to disinfection during the COVID-19 pandemic. Healthcare (Basel) 2020;8(3):232

24 Hindustan Times India. Available at: https://www.hindustantimes.com/india-news/covid-19impacts-dental-surgeriespatients-forced-to-suffer-in-pain/stoy-O7C5iMFVYNG9SOITJ04teK.html. Accessed June 30, 2020

25 Farooq I, Ali S. COVID-19 outbreak and its monetary implications for dental practices, hospitals and healthcare workers. Postgrad Med J 2020;96(1142):791-792 